\title{
A geopolimerização como técnica para a aplicação do resíduo de bauxita
}

\section{(Geopolymerization as a technique for bauxite residue applications)}

\author{
C. S. Bitencourt ${ }^{1}$, B. H. Teider ${ }^{2}$, J. B. Gallo ${ }^{2}$, V. C. Pandolfelli ${ }^{1}$ \\ ${ }^{1}$ Departamento de Engenharia de Materiais, Universidade Federal de S. Carlos, Rod. Washington Luiz, km 235, \\ C. P. 676, S. Carlos, SP 13565-905 \\ ${ }^{2}$ Alcoa Aluminio S.A., Departamento de Aplicações, Desenvolvimentos \& VPE, Rod. Poços Andradas, km 10, \\ Poços de Caldas, $M G$ \\ celina_ufscar@yahoo.com.br,vicpando@power.ufscar.br
}

\begin{abstract}
Resumo
Encontrar aplicações sustentáveis para o resíduo de bauxita tem se mostrado um dos principais desafios da indústria do alumínio na atualidade. Com esse propósito, a geopolimerização pode se tornar uma solução interessante, uma vez que essa técnica seria capaz de tirar proveito de algumas das características mais típicas desse resíduo, como sua elevada alcalinidade e o seu significativo teor de compostos de silício e alumínio, produzindo materiais sólidos semelhantes em propriedades às cerâmicas tradicionais. Neste trabalho, o processamento, as propriedades e as possíveis aplicações dos geopolímeros compostos por resíduo de bauxita foram analisados. Além dos ensaios de porosidade aparente e resistência mecânica, as amostras preparadas também foram submetidas a um ensaio de lixiviação, de modo a já realizar uma avaliação prévia dos potenciais riscos ambientais decorrentes da utilização de um possível produto, e de quais procedimentos favoreceriam a sua passivação. Entre os principais resultados obtidos, verificou-se que a queima a $800{ }^{\circ} \mathrm{C}$ permitiu a algumas das composições desenvolvidas alcançarem valores de resistência à compressão da ordem de até $30 \mathrm{MPa}$, além de uma resistência à lixiviação muito próxima à de um tijolo de argila prensado comum, o que já permite considerar a construção civil como um dos setores mais favoráveis para a aplicação dos geopolímeros com resíduo de bauxita, principalmente pela enorme capacidade de consumo desse setor e da sua crescente demanda por produtos mais sustentáveis. Palavras-chave: resíduo de bauxita, lama vermelha, geopolímero, aplicação.
\end{abstract}

\begin{abstract}
Finding sustainable applications for the bauxite residue is one of the leading challenges in the aluminium industry. For this purpose, the geopolymerization could become an interesting alternative, because this technique could make use of some of the typical characteristics of the bauxite residue, such as its alkalinity and expressive silicates and aluminates contents, resulting in solid materials with similar properties to usual traditional ceramics. In this work, the properties, processing and possible applications of such materials were analyzed. Besides the apparent porosity and the mechanical resistance tests, the obtained samples were also submitted to a leaching test, aiming to a preliminary evaluation of the potential environmental risks of application that a supposed product would represent, and which procedures could favour its passivation. As the main results, it was possible to verify that firing at $800^{\circ} \mathrm{C}$ allowed some compositions to reach compression resistance values up to $30 \mathrm{MPa}$, and a leaching resistance closer to a common pressed clay brick, which makes the building materials a potential area of application for the bauxite residue geopolymers, based on the enormous consumption capacity of this area and its increasing demand for more sustainable products.
\end{abstract}

Keywords: bauxite residue, red mud, geopolymer, application.

\section{INTRODUÇÃO}

Classificado como perigoso pelas normas internacionais em razão da sua elevada alcalinidade, o resíduo de bauxita, também conhecido como lama vermelha, vem sendo disposto predominantemente em aterros especialmente projetados, de modo a assegurar a preservação do solo e das águas subterrâneas. Entretanto, com o aumento da demanda pelo alumínio e com a queda da qualidade das reservas de minério de bauxita, projeta-se uma tendência de crescimento para a geração desse resíduo, a qual, em média, já está em mais de uma tonelada para cada tonelada de alumina produzida ao final do processo Bayer [1]. Com tal perspectiva e com a necessidade de se promover cada vez mais a sustentabilidade do meio industrial, este trabalho investiga o uso da técnica da geopolimerização como ferramenta para conter o resíduo de bauxita na forma de um sólido coeso, com propriedades que lhe permitam agregar valor. Os geopolímeros podem ser definidos como polímeros inorgânicos em que tetraedros de $\mathrm{SiO}_{4}^{4-}$ e $\mathrm{AlO}_{4}^{5-}$ formam uma rede tridimensional ao se ligarem pelo compartilhamento de todos os seus átomos de oxigênio, devendo essa rede ser estabilizada pela presença de cátions monovalentes tais como $\mathrm{Na}^{+}$e $\mathrm{K}^{+}[2,5]$. Sua síntese se dá a partir das reações entre fontes de silicoaluminatos em um meio aquoso e alcalino, sendo que a estrutura do sólido obtido varia entre completamente amorfa a semicristalina [2, 8]. Observando-se as características necessárias aos seus reagentes, é possível chegar à conclusão 
da existência de uma grande possibilidade de que os processos de geopolimerização sejam capazes de consumir o resíduo de bauxita como uma matéria-prima, fazendo uso justamente da sua alcalinidade e dos seus representativos teores de água e de compostos de silício e alumínio. Nisso, um elevado aproveitamento do resíduo de bauxita para a produção de geopolímeros poderia ser alcançado, algo que pode ser considerado como indispensável para a viabilidade econômica de qualquer processo que envolva esse rejeito, visto, como já mencionado acima, a elevada escala em que ocorre a sua geração. Embora venham sendo desenvolvidos desde a metade do século XX, apenas nos últimos dez anos a ciência dos geopolímeros passou a ser alvo de estudos mais intensos, podendo-se destacar como alguns dos seus principais especialistas da atualidade os australianos van Deventer, Lukey, Provis e Duxson, e os americanos Kriven e Bell, os quais têm publicado um grande número de trabalhos orientados tanto para a compreensão dos processos de geopolimerização, visto que sua base teórica ainda está em desenvolvimento, como para a análise das efetivas propriedades dos geopolímeros, de modo a verificar em quais aplicações esses materiais seriam viáveis tecnicamente e competitivos [4, 6, 8-10].

A construção civil tem sido o setor mais visado para o emprego dos geopolímeros, uma vez que suas propriedades podem ser muito similares, ou até mesmo superiores, às dos materiais cerâmicos aplicados nesse campo, no que se incluem as cerâmicas vermelhas, cimentos, concretos, entre outros. No entanto, o maior diferencial dos geopolímeros em relação a esses produtos convencionais estaria em seus aspectos quanto à sustentabilidade, pois os processos de geopolimerização poderiam ser energeticamente menos intensivos (em comparação ao processo de produção do cimento Portland, por exemplo) e, principalmente, poderiam fazer uso de materiais cujo aproveitamento tem se transformado em uma questão de interesse mundial, que são justamente os resíduos industriais [2, 3, 7, 8]. Dentre esses, as cinzas volantes e as escórias siderúrgicas destacam-se como os alvos de maior interesse e estudo. Inclusive, os pesquisadores australianos mencionados acima novamente concentram grande parte das publicações sobre a geopolimerização desses resíduos [11-13], sendo possível também citar outros autores relevantes como Bakharev [14, 15] e Škvára [16, 17]. Quanto à Kriven e Bell, esses possuem seus trabalhos centrados nos geopolímeros produzidos a partir do metacaulim, um silico-aluminato obtido com a calcinação da caulinita e muito aplicado nas pesquisas sobre esses materiais [2].

Quanto ao resíduo de bauxita, esse chega a ser mencionado em alguns estudos como uma possibilidade para o aproveitamento através dos métodos de geopolimerização $[2,3]$. Apesar disso, na literatura foram encontrados apenas dois artigos que trabalham especificamente com esse resíduo $[18,19]$, sendo que ambos consideram o resíduo de bauxita apenas como um filler inativo, ou seja, como se não estivesse contribuindo para as reações de geopolimerização. No entanto, a compreensão dos métodos aplicados e dos resultados apresentados nesses trabalhos foi prejudicada devido a dois pontos relevantes. Em [18] foram utilizados 10\% de piche em suas composições, o que não é um procedimento comum para a produção de geopolímeros. Já em [19] aplicam um resíduo de bauxita cuja composição apresenta um teor de óxidos alcalinos demasiadamente baixo, inferior a $1 \%$ em peso considerando a soma dos teores de $\mathrm{Na}_{2} \mathrm{O}$ e $\mathrm{K}_{2} \mathrm{O}$, algo atípico para esse material e que poderia justificar sua baixa participação nas reações de geopolimerização. Assim, verifica-se que a geopolimerização ainda é uma ferramenta pouco explorada como possível solução para o resíduo de bauxita, o que confere a este trabalho um caráter inovador. Adicionalmente, como as diversas alternativas já cogitadas pelo mundo para a aplicação desse subproduto resultaram em pouco sucesso, o surgimento de mais uma opção deve ser sempre considerado como uma grande oportunidade pela indústria do alumínio.

\section{MATERIAIS E MÉTODOS}

\section{Escolha das matérias-primas e planejamento das composições}

Segundo diversas fontes na literatura, o geopolímero obtém suas melhores propriedades mecânicas quando sua formulação permite que as razões molares $\mathrm{SiO}_{2}$ $\mathrm{Al}_{2} \mathrm{O}_{3}$ e $\mathrm{Al}_{2} \mathrm{O}_{3} / \mathrm{M}_{2} \mathrm{O}$ atinjam valores em torno de 3,8 e 1,0, respectivamente (com $\mathrm{M}_{2} \mathrm{O}$ representando a somatória dos teores dos óxidos alcalinos $\mathrm{K}_{2} \mathrm{O}$ e $\mathrm{Na}_{2} \mathrm{O}$ ) [2, 4, 5, 9]. Assim, para atender a tais condições, o resíduo de bauxita (RB) coletado teve sua composição química definida para que então pudesse ser complementado com os teores adequados de microssílica (microsilica 971U, Elkem), metacaulim (metacaulim HP, Metacaulim do Brasil Ind. Com.) e $\mathrm{KOH}$ (grau PA, Vetec). Para garantir a homogeneidade da amostra de RB, a mesma (contendo cerca de 40\%p água) foi seca a $130{ }^{\circ} \mathrm{C}$ e então desaglomerada por moagem. Sua análise química apresentou como componentes principais $\mathrm{Al}_{2} \mathrm{O}_{3}$ (24\%p), $\mathrm{Fe}_{2} \mathrm{O}_{3}\left(23 \%\right.$ p), $\mathrm{SiO}_{2}$ (17\%p) e $\mathrm{Na}_{2} \mathrm{O}$ (11\%p), cujos teores estão de acordo com o que é considerado como típico para esse resíduo. Quanto às demais matérias-primas escolhidas, decidiu-se pelo uso do $\mathrm{KOH}$ ao invés do $\mathrm{NaOH}$ em razão das propriedades superiores que a literatura apresenta para os geopolímeros formados por combinações entre esses dois cátions alcalinos [2, 4, 6]. Portanto, os íons $\mathrm{Na}^{+}$provenientes do $\mathrm{RB}$ estariam sendo combinados com os íons $\mathrm{K}^{+}$fornecidos pelo $\mathrm{KOH}$. A algumas composições, além do $\mathrm{KOH}$, também foi feita a adição de $\mathrm{Ca}(\mathrm{OH})_{2}$, o que poderia estar promovendo as propriedades de resistência mecânica e resistência à lixiviação $[2,3,7]$. O metacaulim é um dos principais silico-aluminatos usados no estudo e na produção de geopolímeros [2]. Sendo ele e o RB as únicas fontes de grupos $\mathrm{AlO}_{4}{ }^{5-}$ entre as matérias-primas em uso, o teor de ambos precisou ser adequado para atingir a razão $\mathrm{SiO}_{2} / \mathrm{Al}_{2} \mathrm{O}_{3}$ escolhida. Inclusive, os teores dessas duas matérias-primas foram os principais parâmetros variados entre as composições desenvolvidas, justamente com o 
Tabela I - Descrição, em porcentuais em peso, das composições de geopolímeros preparadas, mantendo-se constantes as razões molares $\mathrm{SiO}_{2} / \mathrm{Al}_{2} \mathrm{O}_{3}=3,8$ e $\mathrm{Al}_{2} \mathrm{O}_{3} / \mathrm{M}_{2} \mathrm{O}=1,0$.

[Table I-Compositions in wt.\%, of the prepared geopolymers, keeping constant the molar ratios $\mathrm{SiO}_{2} / \mathrm{Al}_{2} \mathrm{O}_{3}=3.8$ and $\mathrm{Al}_{2} \mathrm{O}_{3} / \mathrm{M}_{2} \mathrm{O}=1.0$.]

\begin{tabular}{cccccc}
\hline Comp. & $\% \mathrm{RB}$ & $\%\left(\mathrm{~K}_{2} \mathrm{O}+\mathrm{Na}_{2} \mathrm{O}\right)$ & $\% \mathrm{Fe}_{2} \mathrm{O}_{3}$ & $\% \mathrm{Ca}(\mathrm{OH})_{2}$ & $\% \mathrm{H}_{2} \mathrm{O}$ \\
\hline $\mathrm{G}-1$ & 72,3 & 11,3 & 17,2 & - & 35,2 \\
$\mathrm{G}-1 / \mathrm{Ca}$ & 67,9 & 10,6 & 16,2 & 6,0 & 35,2 \\
$\mathrm{G}-2$ & 54,1 & 13,7 & 13,3 & - & 35,2 \\
$\mathrm{G}-2 / \mathrm{Ca}$ & 50,8 & 12,9 & 12,5 & 6,0 & 35,2 \\
$\mathrm{G}-3$ & 49,9 & 14,2 & 12,4 & - & 35,2 \\
$\mathrm{G}-3 / \mathrm{Ca}$ & 46,9 & 13,3 & 11,6 & 6,0 & 35,2 \\
$\mathrm{G}-4$ & 43,2 & 15,0 & 10,9 & - & 35,2 \\
$\mathrm{G}-4 / \mathrm{Ca}$ & 40,6 & 14,1 & 10,3 & 6,0 & 35,2 \\
\hline
\end{tabular}

intuito de verificar qual seria o teor de RB máximo aceitável para manter um determinado nível ótimo de propriedades (uma vez que vários trabalhos já atestaram as boas propriedades obtidas para os geopolímeros compostos por metacaulim $[2,6])$. Quanto à microssílica, a escolha desta foi baseada na necessidade de uma fonte de sílica de alta pureza e reatividade, uma vez que tanto o metacaulim como o resíduo de bauxita apresentam teores $\mathrm{de}_{\mathrm{SiO}_{2}}$ e $\mathrm{Al}_{2} \mathrm{O}_{3}$ muito próximos em número de mols, impossibilitando que juntos alcançassem a razão $\mathrm{SiO}_{2} / \mathrm{Al}_{2} \mathrm{O}_{3}=3,8$. O uso de silicatos de sódio e de potássio ao invés da microssílica chegou a ser cogitado, mas esses não poderiam fornecer a quantidade necessária de $\mathrm{SiO}_{2}$ sem que o teor de álcalis desejado fosse excedido.

As composições desenvolvidas estão descritas na Tabela I com relação aos seus teores finais de RB, óxido de ferro (proveniente do RB), óxidos alcalinos (provenientes do RB e do $\mathrm{KOH}$ ), hidróxido de cálcio e água. Os números de $1 \mathrm{a}$ 4 que compõem suas nomenclaturas indicam o crescimento do teor de metacaulim (e, portanto, o decréscimo do teor de $\mathrm{RB}$ ), enquanto a notação " $\mathrm{Ca}$ " indica a adição de $6 \% \mathrm{p}$ de $\mathrm{Ca}(\mathrm{OH})_{2}$.

Como mencionado anteriormente, as proporções entre as matérias-primas foram determinadas de modo que todas as composições atingissem as razões molares $\mathrm{SiO}_{2} /$ $\mathrm{Al}_{2} \mathrm{O}_{3}=3,8$ e $\mathrm{Al}_{2} \mathrm{O}_{3} / \mathrm{M}_{2} \mathrm{O}=1,0$. Considerou-se que todos os compostos que poderiam colaborar para a formação da estrutura geopolimérica (compostos de silício, alumínio e álcalis) seriam completamente dissolvidos pelo meio básico da solução de $\mathrm{KOH}$, ficando, assim, disponíveis para reagir. Porém, sabendo-se que essa dissolução completa não é possível, principalmente para o RB ou mesmo para o metacaulim, já se planeja para outras etapas desta pesquisa variar ambas as razões molares de forma a verificar se haveriam valores mais favoráveis para a geopolimerização do RB. Como se verifica pela Tabela I, para todas as composições o teor de água também foi mantido constante em 35,2\% em peso. Esse valor elevado foi necessário para permitir a moldagem das amostras por fluência sob vibração, uma vez que a granulometria fina de todas as matérias-primas não permitiria um bom empacotamento entre elas, visto que as razões molares da geopolimerização ainda precisariam ser satisfeitas. Além disso, não foram encontrados dispersantes que pudessem melhorar significativamente a fluidez desses sistemas, uma provável conseqüência do elevado $\mathrm{pH}$ atingido por todos eles (acima de 14). Entretanto, em experimentos mais recentes, a modificação do método de mistura com o uso de misturadores mais potentes e com a alteração da ordem de adição das matérias-primas já permitiu que o teor de água fosse reduzido a $25 \%$ p para algumas composições, isso sem que a fluidez fosse prejudicada.

\section{Métodos de processamento e cura}

As composições foram preparadas em um misturador de bancada e conformadas em moldes cilíndricos de $30 \mathrm{~mm}$ de diâmetro por $35 \mathrm{~mm}$ de altura. Após a moldagem, os moldes foram selados com filmes plásticos e deixados em processo de cura por 3 dias em condições ambientes. Fez-se então a desmoldagem das amostras e o processo de cura continuou por mais 5 dias em uma câmara climática a $50{ }^{\circ} \mathrm{C}$ e $100 \%$ de umidade relativa. Terminada a etapa de cura, as amostras foram secas em uma estufa a $50{ }^{\circ} \mathrm{C}$ por $24 \mathrm{~h}$. Grupos de amostras foram então submetidos a tratamentos térmicos a 200,400 , 600 e $800{ }^{\circ} \mathrm{C}$, com uma taxa de aquecimento de $3{ }^{\circ} \mathrm{C} / \mathrm{min}$, com patamar de queima de $2 \mathrm{~h}$ na temperatura máxima. Tanto as amostras apenas curadas como as tratadas termicamente foram avaliadas com relação às variações dimensionais, à porosidade aparente (ASTM-C830) e quanto à resistência à compressão uniaxial (ASTM-C133-94, com uma taxa de carregamento igual a $140 \mathrm{~N} / \mathrm{s}$ ). Os resultados para tais ensaios expressam a média dos valores obtidos para cinco amostras.

Com a intenção de analisar a capacidade da geopolimerização para passivar o resíduo de bauxita, o que poderá ser um fator essencial para que esses materiais sejam considerados aplicáveis, ensaios de lixiviação foram conduzidos avaliando-se uma amostra de cada composição e temperatura de tratamento. Este ensaio consistiu em se submeter a amostra de geopolímero a cerca de 90 ciclos de lixiviação (com duração de $~ 20$ min cada um), com 
água deionizada aquecida a $80{ }^{\circ} \mathrm{C}$ como meio lixiviante. $\mathrm{O}$ equipamento utilizado na realização desse teste consistiu no sistema de extração contínua apresentado na Fig. 1, no qual a água contida no balão de vidro é evaporada pela ação da manta térmica, sendo esse vapor novamente liquefeito ao atingir o condensador de bolas. Nisso, a água se precipita sobre a amostra contida no extrator, realizando a lixiviação. O lixiviado formado chega a se acumular no extrator, mas escorre novamente para o balão de vidro à medida que cada ciclo chega ao fim (aumentando, conseqüentemente, a concentração da solução no balão). Durante as $24 \mathrm{~h} \mathrm{em}$ que o ensaio se processava, o lixiviado contido no balão foi analisado quanto ao seu $\mathrm{pH}$ (pHmetro Hanna Instr. HI $98108 \mathrm{pHep}+$ ) e sua condutividade elétrica (condutivímetro Oakton TDSTestr 20) a cada intervalo de $1 \mathrm{~h}$.

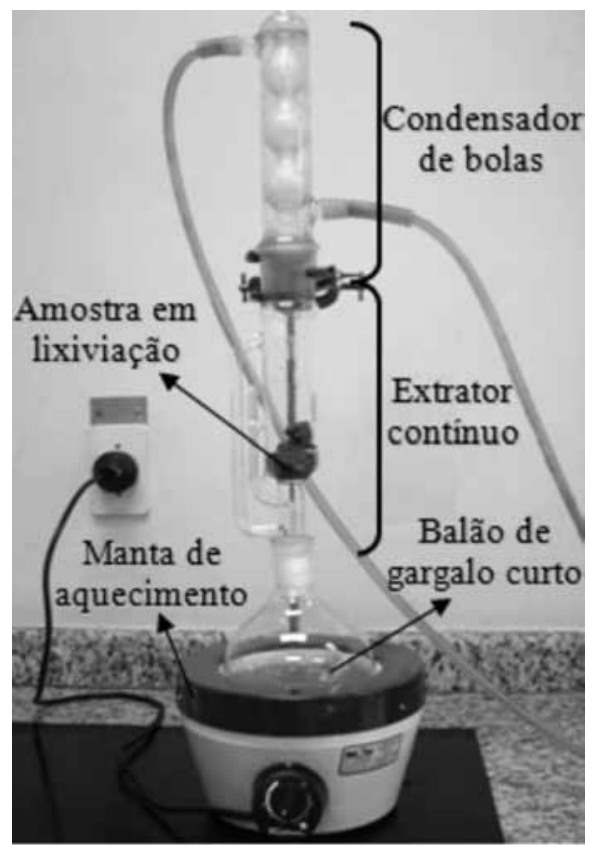

Figura 1: Sistema de extração contínua usado nos ensaios de lixiviação.

[Figure 1: Continuous extraction system used for the leaching tests.]

\section{RESULTADOS E DISCUSSÃO}

\section{Observações durante a etapa de processamento}

Apesar do teor de água ter se mantido constante, ficou nítida ao longo dos processos de mistura uma significativa redução da fluidez da composição G-4 para a composição G-1, ou seja, à medida que se diminuía o teor de metacaulim e se elevava o teor de RB. Cogita-se que esse comportamento se deva ao menor tamanho de partícula do metacaulim e a sua maior solubilidade no meio alcalino quando comparado ao RB, o que propiciaria uma menor quantidade de sólidos em suspensão à medida que o primeiro substituísse o segundo. Além disso, para atingir a razão $\mathrm{Al}_{2} \mathrm{O}_{3} / \mathrm{M}_{2} \mathrm{O}=$ 1,0 , foi necessário aumentar o teor de $\mathrm{KOH}$ conforme se elevava o de metacaulim (já que o último não é uma fonte de álcalis como o RB). Assim, sendo o $\mathrm{KOH}$ mais alcalino [2] e certamente mais solúvel que os compostos de sódio provenientes do resíduo de bauxita, o $\mathrm{pH}$ das composições acabou sofrendo pequenos incrementos de G-1 para G-4, o que certamente favoreceu uma maior dissolução de todas as matérias-primas. Entretanto, a fluidez sofreu uma queda ainda mais expressiva quando da adição dos $6 \%$ p de $\mathrm{Ca}(\mathrm{OH})_{2}$ para qualquer uma das quatro composições originais, dificultando muito a moldagem dessas amostras. Em vista da alta reatividade entre o hidróxido de cálcio e a microssílica [8], é quase certo que essa queda de fluidez se deva à rápida formação de um gel de silicato de cálcio hidratado de alta viscosidade. Passando-se à etapa de cura, também foi muito perceptível nos 3 primeiros dias uma aceleração do ganho de resistência com o aumento do teor de metacaulim entre as composições. Porém, é possível que tal efeito também se deva à elevação concomitante do teor de $\mathrm{KOH}$ comentada anteriormente, pois é confirmado que o aumento do teor dessas duas matérias-primas leva à redução do tempo de cura do geopolímero [2].

Quanto às composições aditivadas com $\mathrm{Ca}(\mathrm{OH})_{2}$, todas já apresentaram uma boa resistência física um dia após a moldagem. O impacto da adição desse componente pôde ser observado principalmente por meio das composições G-1 e G-1/Ca. A composição G-1, a qual contém os menores teores de metacaulim e de $\mathrm{KOH}$ dentre todas, acabou não adquirindo resistência suficiente nos primeiros 3 dias de cura, levando suas amostras a se deformarem durante a desmoldagem. Porém, adicionando-se o $\mathrm{Ca}(\mathrm{OH})_{2}$ (composição $\mathrm{G}-1 / \mathrm{Ca}$ ), o ganho de resistência ocorreu em menos de $24 \mathrm{~h}$, assim como para as outras composições aditivadas com esse hidróxido. Devido à deformação de suas amostras não foi possível avaliar quaisquer propriedades do geopolímero G-1. A adição de $\mathrm{Ca}(\mathrm{OH})_{2}$ também propiciou amostras visualmente mais homogêneas quanto à coloração e com um melhor acabamento externo. Sem o hidróxido de cálcio, pôde-se notar a formação de uma camada escurecida ao redor das amostras quando se comparam suas faces lateral e superior, como exemplifica a amostra da composição G-4 na Fig. 2. Por outro lado, para todas as composições aditivadas com $\mathrm{Ca}(\mathrm{OH})_{2}$, é possível verificar a existência de minúsculos pontos brancos distribuídos por todo o volume das amostras, como demonstra a região ampliada da face superior da amostra da composição G-4/Ca na Fig. 2. Por uma análise visual, a quantidade desses pontos brancos aumenta conforme se eleva o teor de metacaulim de G-1/ $\mathrm{Ca}$ para G-4/Ca. Porém, tal comportamento poderia ser considerado contraditório caso esses pontos brancos sejam formados pelo próprio $\mathrm{Ca}(\mathrm{OH})_{2}$, uma vez que o metacaulim deveria ser muito susceptível a desenvolver reações pozolânicas na presença desse hidróxido [20].

No entanto, esse comportamento também poderia ser uma conseqüência da elevação do $\mathrm{pH}$ proporcionada pela maior adição do hidróxido de potássio para as composições com mais metacaulim, visto que $\mathrm{pH}$ 's elevados prejudicam a solubilidade e, portanto, a reatividade do $\mathrm{Ca}(\mathrm{OH})_{2}[3]$. 

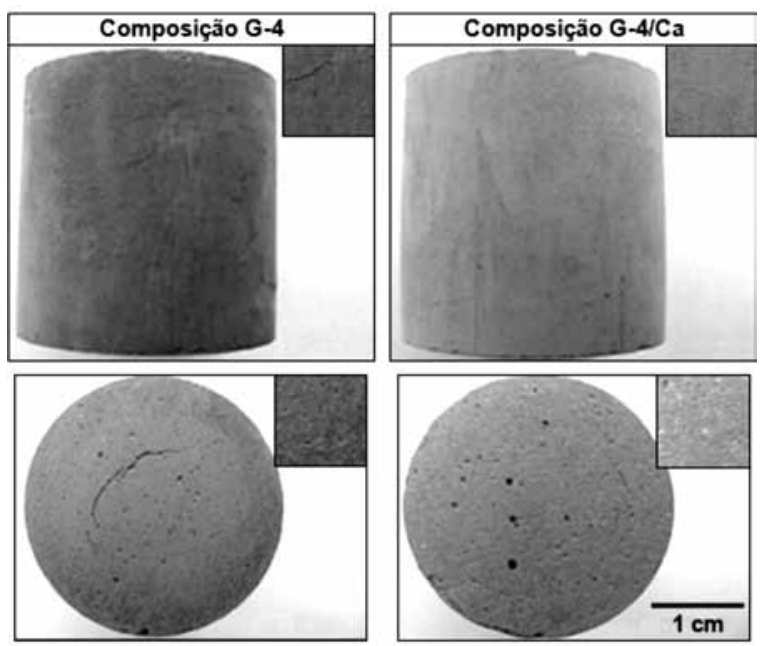

Figura 2: Visão lateral e superior das composições G-4 e G-4/Ca, após tratamento térmico a $200{ }^{\circ} \mathrm{C}$.

[Figure 2: Front and top view of the ccompositions $G-4$ and $G-4$ / Ca after thermal treatment at $200^{\circ} \mathrm{C}$.]

\section{Resultados dos ensaios laboratoriais}

A dependência do efeito do $\mathrm{Ca}(\mathrm{OH})_{2}$ com o teor de metacaulim já pôde ser confirmada pelos resultados de retração dimensional das amostras após a cura e após os tratamentos térmicos, que são apresentados na Fig. 3. Até $600{ }^{\circ} \mathrm{C}$ a retração de todas as composições sem $\mathrm{Ca}(\mathrm{OH})_{2}$ é muito semelhante. Com a adição do hidróxido, a retração diminui para todas as composições, havendo uma tendência de se tornar menor ainda conforme ocorre a redução do teor de metacaulim e o aumento do teor de RB de G-4/Ca para G-1/Ca. No entanto, esse comportamento se inverte totalmente acima de $600{ }^{\circ} \mathrm{C}$ : as composições aditivadas com $\mathrm{Ca}(\mathrm{OH})_{2}$ agora apresentam uma maior retração que

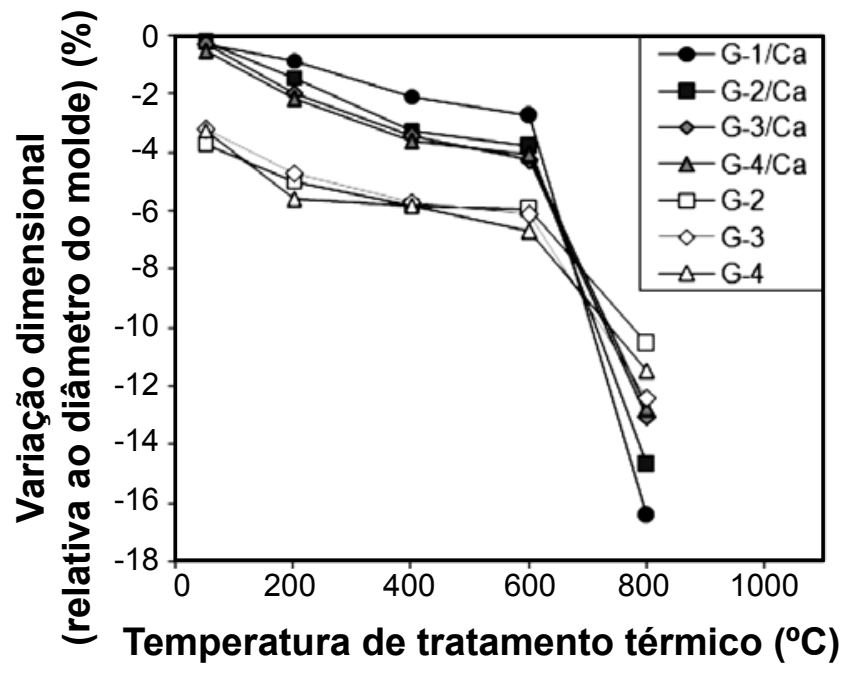

Figura 3: Variação dimensional das amostras em função da temperatura de tratamento térmico (os resultados referentes a $50{ }^{\circ} \mathrm{C}$ são relativos às amostras curadas e secas).

[Figure 3: Samples dimensional variation with the temperature of thermal treatment (the results at $50{ }^{\circ} \mathrm{C}$ refer to the samples after the drying step).]

as demais, e o valor dessa retração passa a aumentar com o aumento do teor de RB. Tal inversão seria resultado das reações entre o cálcio [7] e as grandes quantidades de álcalis e óxido de ferro provenientes do $\mathrm{RB}$, que levam à formação de fases líquidas de baixa viscosidade, as quais também proporcionaram uma grande queda da porosidade aparente a $800{ }^{\circ} \mathrm{C}$, Fig. 4. Além disso, confrontando-se esses gráficos também é possível observar que, apesar dos valores de retração se diferenciarem em até 3\% na Fig. 3, quando se comparam os pares de composições G-X e G-X/ $\mathrm{Ca}$ até $600{ }^{\circ} \mathrm{C}(\operatorname{com} \mathrm{X}=2,3 \mathrm{e} 4)$, tais diferenças parecem

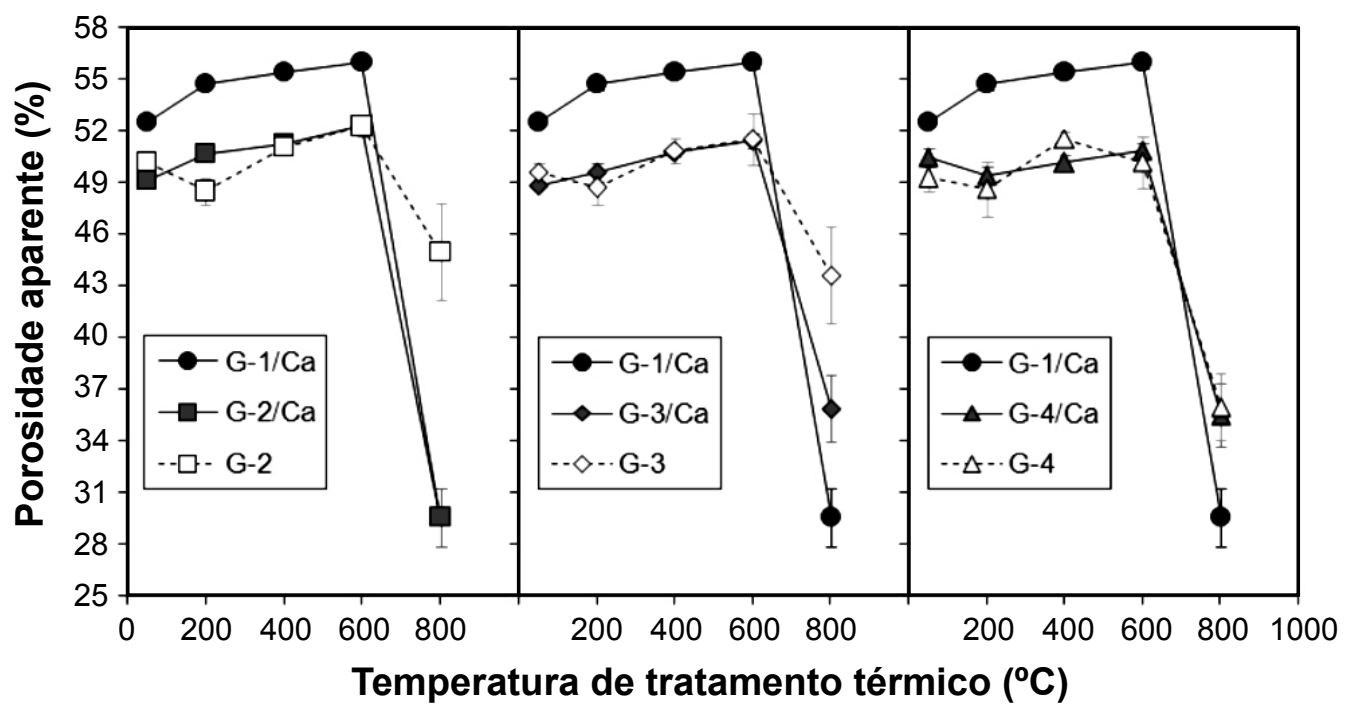

Figura 4: Porosidade aparente em função da temperatura de tratamento térmico (os resultados referentes a $50^{\circ} \mathrm{C}$ são relativos às amostras curadas e secas).

[Figure 4: Apparent porosity as a function of the thermal treatment temperature (the results at $50{ }^{\circ} \mathrm{C}$ refer to the samples after the drying step).] 
não se refletirem na porosidade aparente, visto que ocorre praticamente uma sobreposição dos valores de porosidade para esses mesmos pares de composições na Fig. 4. Esse comportamento sugere que a presença do hidróxido de cálcio propiciaria a ocorrência de reações expansivas já a baixas temperaturas.

Os resultados dos ensaios de compressão uniaxial para as sete composições são apresentados na Fig. 5. Apesar da grande retração dimensional a $800{ }^{\circ} \mathrm{C}$ ter levado à formação de várias trincas em todas as amostras, verificase pelos gráficos que a resistência mecânica alcança seus valores máximos justamente nessa temperatura. Para as composições contento hidróxido de cálcio, novamente há uma melhoria das suas propriedades conforme se reduz o teor de metacaulim e se eleva o teor de RB. No entanto, mesmo a $800^{\circ} \mathrm{C}$, os resultados obtidos para essas composições foram inferiores aos daquelas isentas desse hidróxido.

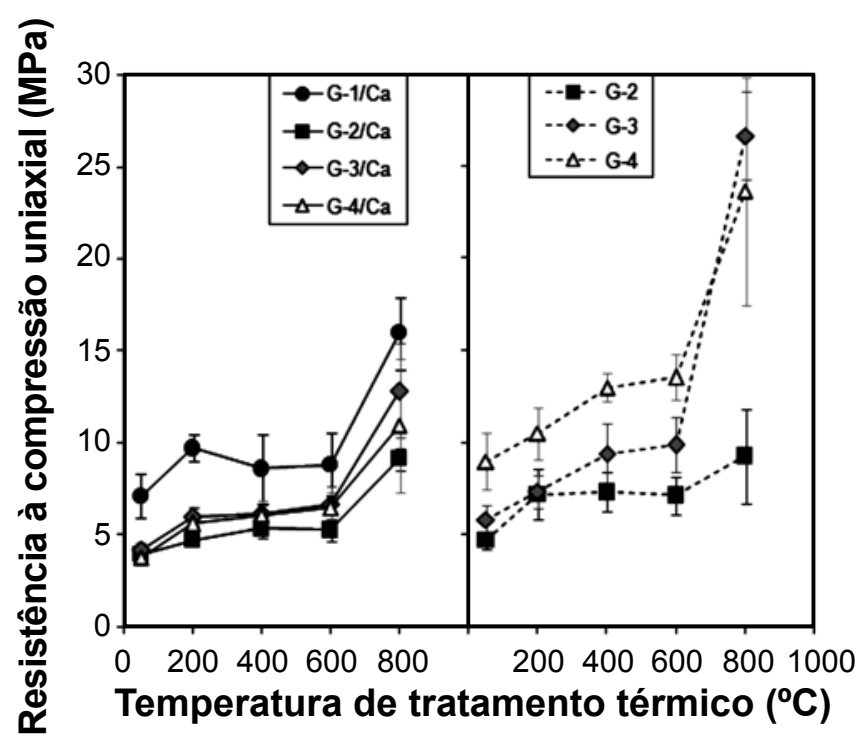

Figura 5: Módulo de ruptura sob compressão uniaxial em função da temperatura de tratamento térmico (os resultados referentes a $50{ }^{\circ} \mathrm{C}$ são relativos às amostras curadas e secas).

[Figure 5: Modulus of rupture under uniaxial compression as a function of the thermal treatment temperature (the results at $50{ }^{\circ} \mathrm{C}$ refer to the samples after the drying step).]

Além disso, na ausência do $\mathrm{Ca}(\mathrm{OH})_{2}$, são as composições com os menores teores de RB que passam a atingir os melhores resultados de resistência à compressão para todas as temperaturas, chegando a valores de tensão de fratura da ordem de $29 \mathrm{MPa}$ a $800{ }^{\circ} \mathrm{C}$. Adicionalmente, como os resultados a essa temperatura sugerem, o efeito do teor de RB parece ter sido especialmente crítico para os resultados de resistência mecânica entre as composições G-2 e G-3, ou seja, quando o teor total de RB é reduzido de 54,1 para $49,9 \%$ em peso. Portanto, apesar das vantagens trazidas no tempo de cura e no aspecto externo das amostras, o $\mathrm{Ca}(\mathrm{OH})_{2}$ prejudicou significativamente a resistência mecânica das composições de geopolímeros com RB. Ainda não há uma explicação definitiva para tal comportamento, mas, como o hidróxido de cálcio e a microssílica costumam ser muito reativos entre si, supõe-se a possível formação de uma camada de silicato de cálcio hidratado ao redor das partículas de microssílica, o que então evitaria a reação completa da última para formar a estrutura do geopolímero. Assim, a efetiva razão $\mathrm{SiO}_{2} / \mathrm{Al}_{2} \mathrm{O}_{3}$ da fase geopolimérica estaria abaixo do valor ideal de 3,8 , o que justificaria a obtenção de propriedades mecânicas inferiores. Caso tal hipótese seja verdadeira, os pontos brancos observados nas amostras aditivadas com $\mathrm{Ca}(\mathrm{OH})_{2}$ seriam, na verdade, constituídos por essas partículas ou aglomerados de microssílica que não reagiram completamente, envolvidos pela fase de silicato de cálcio hidratado. Considerando-se os valores de resistência mecânica alcançados pelas composições apenas curadas, logo se verifica que esses ficaram muito abaixo do que é usualmente obtido para os geopolímeros compostos por cinzas volantes e escórias siderúrgicas, os quais costumam ultrapassar os $40 \mathrm{MPa}$ em resistência à compressão [2-4, 6-8, 13-17]. Tal diferença tão significativa pode ser atribuída principalmente à menor reatividade do $\mathrm{RB}$ e ao seu grande teor de componentes que não participariam das reações de geopolimerização (como os óxidos de ferro, por exemplo) em comparação a esses outros resíduos. Além disso, os geopolímeros desenvolvidos na literatura costumam ser processados com teores de água inferiores a $26 \%$ em peso, enquanto nestas composições com RB utilizou-se $35,2 \%$. Portanto, a porosidade dos primeiros seria significativamente menor, causando um prejuízo menos expressivo as suas propriedades mecânicas.

No entanto, os valores de resistência à compressão uniaxial obtidos para as sete composições desenvolvidas já são mais que suficientes para tornar os geopolímeros compostos por resíduo de bauxita candidatos à aplicação no setor da construção civil, pois a norma brasileira NBR-6460 estabelece que tijolos de argila prensados são adequados para uso quando apresentam resistência à compressão da ordem de 1,5 a $4 \mathrm{MPa}$ [21]. Porém, maior que o interesse de se atingir boas propriedades mecânicas é o de garantir que a aplicação dos geopolímeros desenvolvidos não represente um risco à segurança da sociedade e do meio ambiente. Para avaliar tal possibilidade, amostras das sete composições preparadas foram submetidas a ensaios de lixiviação, cujos resultados para as composições G-4 e G-4/Ca, tratadas a 600 e $800{ }^{\circ} \mathrm{C}$, são apresentados nas Figs. 6 e 7. Para qualificar a resistência à lixiviação desses geopolímeros, tomou-se como referência o resultado do ensaio de lixiviação de uma amostra de tijolo de argila comum (que já se encontrava queimado), uma vez que essa é uma das aplicações em foco e também por se tratar de um produto constantemente submetido a solicitações de intemperismo.

Tanto os resultados do acompanhamento do $\mathrm{pH}$ quanto da condutividade elétrica do lixiviado apontam que a queima dos geopolímeros com resíduo de bauxita a temperaturas inferiores a $600^{\circ} \mathrm{C}$ é insuficiente para passivar suas estruturas e, assim, evitar a lixiviação de íons. Já na queima a $800{ }^{\circ} \mathrm{C}$ o comportamento das composições G-4 e G-4/Ca torna-se muito mais próximo ao do tijolo de argila, principalmente 


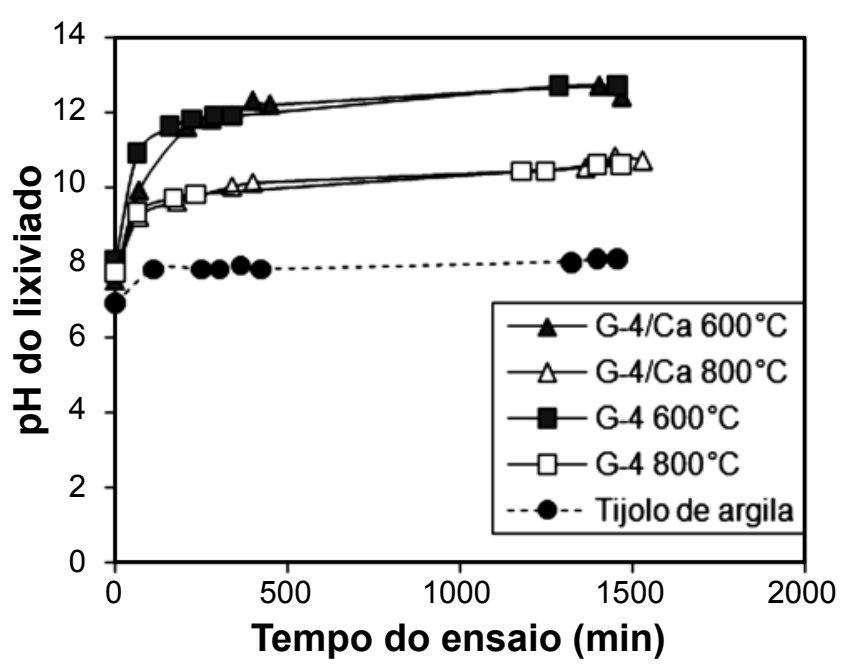

Figura 6: $\mathrm{pH}$ do lixiviado em função do tempo de ensaio. [Figure 6: $p H$ of the leachate as a function of time.]

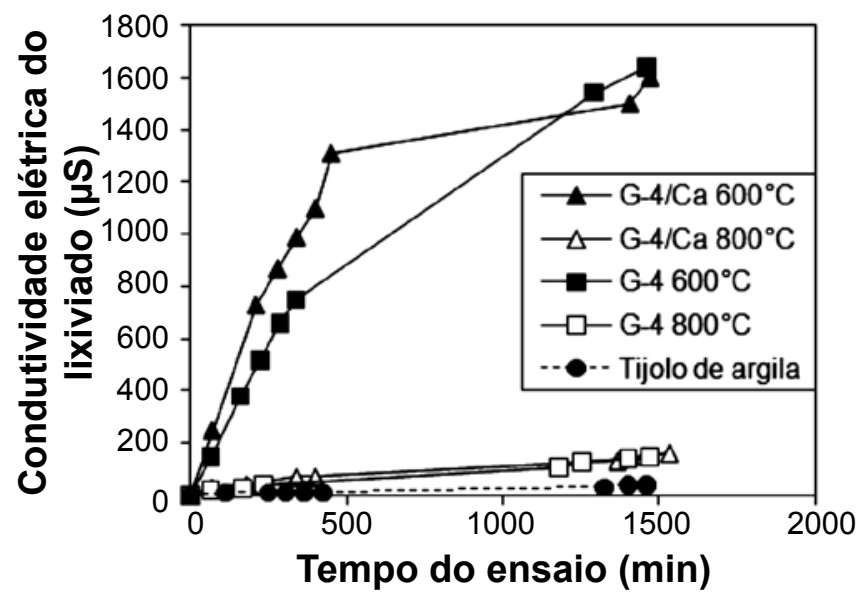

Figura 7: Condutividade elétrica do lixiviado em função do tempo de ensaio.

[Figure 7: Eletrical condutivity of the leachate as a function of time.]

de acordo com os resultados de condutividade elétrica, que ficaram abaixo dos $160 \mu \mathrm{S}$ para ambas as composições. Quanto ao efeito da adição do hidróxido de cálcio, esta não parece ter trazido os benefícios à resistência à lixiviação que a literatura sugeria, mas isso pode ser uma consequência da sua reação incompleta ou da sua reação preferencial com a microssílica, como foi conjecturado anteriormente. Os resultados obtidos para as demais composições se assemelham muito aos das composições G-4 e G-4/Ca. Assim, constata-se que a sinterização dos geopolímeros com resíduo de bauxita é essencial para promover a sua resistência à lixiviação pela água. Porém, essa propriedade ainda precisa ser otimizada em vista do elevado $\mathrm{pH}$ que as amostras queimadas a $800{ }^{\circ} \mathrm{C}$ alcançaram (próximo a 10,5), e da grande possibilidade de que seja exigido para tais materiais uma resistência à lixiviação superior à do material padrão usado na aplicação que lhes forem cogitadas (como a dos tijolos de argila, no caso da construção civil), uma vez que se trata do aproveitamento de um resíduo industrial. As informações fornecidas pela análise química dos líquidos lixiviados poderão proporcionar um grande auxílio para os próximos passos do desenvolvimento desses geopolímeros. Para as composições G-4 e G-4/Ca e em ambas as temperaturas de tratamento, essa análise apresentou que as substâncias mais solvatadas durante o processo de lixiviação foram compostos de silício, potássio e sódio.

Para as amostras tratadas a $600^{\circ} \mathrm{C}$ a proporção entre as concentrações desses dois álcalis nos lixiviados mantevese muito próxima à da existente na formulação das suas composições correspondentes. Como as composições G-4 e $\mathrm{G}-4 / \mathrm{Ca}$ exigiram uma grande adição de $\mathrm{KOH}$ por seus baixos teores de resíduo de bauxita (fonte de $\mathrm{Na}$ ), o potássio acabou sendo mais lixiviado que o sódio. Já para as amostras tratadas a $800^{\circ} \mathrm{C}$ as concentrações de ambos os álcalis nos lixiviados, além de terem sido reduzidas em até 50 vezes em comparação aos das amostras tratadas a $600{ }^{\circ} \mathrm{C}$, também passaram a ser muito similares. Quanto ao silício, os seus composto foram sempre os mais solubilizados tanto a 600 como a $800{ }^{\circ} \mathrm{C}$. Inclusive, a $800{ }^{\circ} \mathrm{C}$, mesmo a somatória da concentração dos álcalis não chega a ultrapassar a concentração de $\mathrm{Si}$ nos lixiviados. Por outro lado, inesperadamente, a livixiviação de compostos de alumínio e ferro foi sempre mínima para qualquer composição ou temperatura. Quanto ao cálcio, mesmo para a composição G-4/Ca, a detecção deste também foi pouco significativa. Tal conjunto de comportamentos dá margem a diversas conclusões e hipóteses. Uma dessas conclusões seria a de que o ferro estaria muito bem estabilizado em meio à estrutura do geopolímero, embora muito provavelmente não esteja participando dela. Nesse caso, o Fe poderia então estar combinado com o alumínio, o que também justificaria a baixa lixiviação deste e a alta lixiviação do silício e dos álcalis, visto que, estando o alumínio apenas parcialmente disponível para formar a fase geopolimérica, a sílica e os álcalis em excesso ficariam totalmente expostos à ação da água. Assim, é possível que a principal fonte de compostos de alumínio que sejam atuantes na geopolimerização esteja realmente no metacaulim. Quanto ao silício lixiviado, sua proveniência ainda é incerta, mas é possível supor que sua origem principal seja a microssílica, já que nessa matériaprima o óxido de silício está como um composto isolado, o que provavelmente facilita a sua retirada da estrutura quando esta é submetida a um meio alcalino. A manutenção da proporção entre os álcalis potássio e sódio no lixiviado das amostras tratadas a $600{ }^{\circ} \mathrm{C}$ sugere que suas fontes foram igualmente lixiviadas. Nisso, como o resíduo de bauxita é a única fonte de sódio, é possível afirmar que ele não estaria apenas como um filler na composição do geopolímero, sendo ao menos um fornecedor de álcalis. Já no tratamento das amostras a $800^{\circ} \mathrm{C}$, o aprisionamento do potássio pela estrutura aparenta ter sido mais efetivo que o do sódio, já que suas concentrações no lixiviado se igualaram apesar da composição G-4 ter uma quantidade de $\mathrm{K}_{2} \mathrm{O}$ duas vezes superior à de $\mathrm{Na}_{2} \mathrm{O}$. 


\section{CONCLUSÕES}

A síntese de geopolímeros a partir do resíduo de bauxita realmente é possível, resultando em materiais com propriedades de resistência mecânica já compatíveis para aplicação no setor da construção civil. Dentre as principais vantagens apresentadas pela geopolimerização no reaproveitamento desse resíduo, destaca-se a sua capacidade de consumi-lo em quantidades elevadas, uma vez que todas as formulações avaliadas continham teores de resíduo superiores a $40 \%$ em peso. Adicionalmente, embora o resíduo usado nos experimentos tenha sido previamente seco e moído, é muito provável que o resíduo in natura (ou seja, úmido) possa ser utilizado diretamente na geopolimerização, sem a necessidade de qualquer prétratamento. A possibilidade de aplicar tais materiais na construção civil também se apresenta muito vantajosa, uma vez que esse setor tem uma capacidade de consumo compatível com a escala de produção do resíduo de bauxita, e já que nos últimos anos a pressão pelo desenvolvimento e a demanda por produtos de construção mais sustentáveis vêm aumentando em todo o mundo. Com relação à dependência das propriedades com as variações na formulação e no processamento dos geopolímeros, alguns comportamentos se mostram claros. 1) A adição de metacaulim favorece a redução do tempo de cura, além de melhores propriedades mecânicas, uma melhor resistência à lixiviação e uma maior refratariedade para esses materiais. Porém, como pode ser considerada uma matéria-prima de custo elevado e como a sua adição também exige o uso de mais $\mathrm{KOH}$, seria necessário estimar um teor máximo no qual ela poderia ser aplicada para que o custo de um possível produto estivesse dentro do que seria considerado viável economicamente. 2) Os benefícios que a sinterização do geopolímero traz tanto para a sua resistência mecânica como para a estabilidade da sua estrutura (ainda assim, outros métodos para promover a resistência à lixiviação precisam ser pesquisados). 3) Quanto à adição do hidróxido de cálcio, essa trouxe os benefícios da possibilidade de se reduzir o tempo de cura e de melhorar o acabamento das amostras. Por outro lado, ela prejudicou as propriedades mecânicas e em nada auxiliou na melhoria da resistência à lixiviação, como a literatura sugeria. Porém, tais comportamentos podem ser devidos a sua reação incompleta, ou ao fato do seu uso realmente estar levando a um consumo incompleto da microssílica para a formação da estrutura do geopolímero. Portanto, é necessário fazer uma análise mais profunda de como e em quais quantidades o hidróxido de cálcio poderia ser aplicado.

Para as próximas etapas deste trabalho, já se tem em vista diversas modificações pertinentes ao processamento dos geopolímeros com resíduo de bauxita, tais como redução do teor de água, adição de agregados para melhoria das propriedades mecânicas e de resistência química, e otimização das razões molares para adequá-las às peculiaridades do resíduo de bauxita (passando-o a considerá-lo apenas como fonte de álcalis e sílica, por exemplo). Entre os resultados recentemente obtidos, destacam-se a influência da ordem de mistura das matérias-primas e do próprio equipamento de mistura usado sobre a fluidez final das composições. Modificando-se esses dois fatores, já está sendo possível cogitar a redução do teor de água para valores abaixo de $25 \%$ em peso, sem que isso prejudique a moldabilidade das amostras.

\section{AGRADECIMENTOS}

À Alcoa Alumínio S.A. pelo apoio financeiro, técnico, e pelo fornecimento e análise das amostras de resíduo, e a F. Tiberti, por toda a sua disposição e empenho na obtenção destes resultados.

\section{REFERÊNCIAS}

[1] V. M. Sglavo, R. Campostrini, S. Maurina, G. Carturan, M. Monagheddu, G. Budroni, G. Cocco, Bauxite 'red mud' in the ceramic industry Part 1: thermal behavior, J. Eur. Ceram. Soc. 20 (2000) 235-244.

[2] K. Komnitsas, D. Zaharaki, Minerals Eng. 20 (2007) 1261-1277.

[3] F. Pacheco-Torgal, J. Castro-Gomes, S. Jalali, Constr. Build. Mater. 22 (2008) 1315-1322.

[4] P. Duxson, S. W. Mallicoat, G. C. Lukey, W. M. Kriven, J. S. J. Van Deventer, Colloids Surfaces A: Physicochem. Eng. Aspects 292 (2007) 8-20.

[5] P. De Silva, K. Sagoe-Crenstil, V. Sirivivatnanon, Cement Concrete Res. 37 (2007) 512-518.

[6] W. M. Kriven, J. L. Bell, Ceram. Eng. Sci. Proc. 25, 4 (2008) 99-104.

[7] K. Dombrowski, A. Buchwald, M. Weil, J. Mater. Sci. 42 (2006) 3033-3043.

[8] P. Duxson, A. Fernández-Jiménez, J. L. Provis, G. C. Lukey, A. Palomo, J. S. J. Van Deventer, J. Mater. Sci. 42 (2007) 2917-2933.

[9] P.Duxson, J.L.Provis, G.C.Lukey, S.W.Mallicoat,W.M. Kriven, J. S. J.van Deventer, Understanding the relationship between geopolymer composition, microstructure and mechanical properties, Colloids Surfaces A: Physicochem. Eng. Aspects 269 (2005) 47-58.

[10] W. M. Kriven, J. L. Bell, M. Gordon, Geopolymer refractories for the glass manufacturing industry, Ceram. Eng. Sci. Proc. 25 (2004) 57-79.

[11] P. Duxson, J. L. Provis, G. C. Lukey, J. S. J. van Deventer, The role of inorganic polymer technology in the development of 'green concrete', Cement Concrete Res. 37 (2007) 1590-1597.

[12] P. Duxson, J. L. Provis, Designing precursors for geopolymer cements, J. Am. Ceram. Soc. 91 (2008) 38643869.

[13] K. C. Goretta, F. Gutierrez-Mora, D. Singh, J. L. Routbort, G. C. Lukey, J. S. J. van Deventer, Erosion of geopolymers made from industrial waste, J. Mater. Sci. 42 (2007) 3066-3072.

[14] T. Bakharev, Thermal behaviour of geopolymers prepared using class F fly ash and elevated temperature 
curing, Cement Concrete Res. 36 (2006) 1134-1147.

[15] T. Bakharev, Geopolymeric materials prepared using class $F$ fly ash and elevated temperature curing, Cement Concrete Res. 35 (2005) 1224-1232.

[16] F. Škvára, L. Kopecký, J. Nemecek, Z. Bittnar, Microstructure of geopolymer material based on fly ash, Silikáty 50, 4 (2006) 208-215.

[17] F. Škvára, T. Jílek, L. Kopecký, Geopolymer based on fly ash, Silikáty 49, 3 (2005) 195-204.

[18] W. Cundi, Y. Hirano, T. Terai, R. Vallepu, A. Mikuni,

K. Ikeda, Preparation of geopolymeric monoliths from red
mud-PFBC ash fillers at ambient temperature, Proc. World Cong. Geopolymer, Saint-Quentin, França (2005) 85-87.

[19] D. D. Dimas, I. P. Giannopoulou, D. Panias, Utilization of alumina red mud for synthesis of inorganic polymeric materials, Mineral Proc. Extract. Metal. Rev. 30 (2009) 211239.

[20] disponível em: <http://www.metacaulim.com.br/ tecnica/tecnica.htm>, acessado em 22/03/2009.

[21] R. C. L. Araujo, E. H. V. Rodrigues, E. G. A. Freitas, Materiais de Construção, Vol. 1, Ed. Univ. Rural, Rio de Janeiro, RJ (2000) 112.

(Rec. 31/07/2009, Rev. 17/08/2009, Ac. 04/09/2009) 